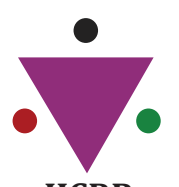

IJCRR

Section: Healthcare

Sci. Journal Impact

Factor: 5.385 (2017)

ICV: 71.54 (2015)

\title{
Awareness of Radiation Protection Among Trainee Dentists of Aurangabad, Maharashtra: A Questionnaire Based Study
}

\section{Ashish Bhaskar Zope ${ }^{1}$, Lata Madhukar Kale², Sonia Kaur Sodhi, Vishwas Dattatratya Kadam ${ }^{4}$, Aishwarya Madhukar Kale ${ }^{5}$}

\begin{abstract}
'P.G. Student, Department of Oral Medicine \& Radiology, C.S.M.S.S. Dental College \& Hospital, Kanchanwadi, Paithan Road, Aurangabad, Maharashtra; ${ }^{2}$ M.D.S., Professor \& H.O.D., Department of Oral Medicine \& Radiology, C.S.M.S.S. Dental College \& Hospital, Kanchanwadi, Paithan Road, Aurangabad, Maharashtra; ${ }^{3}$ M.D.S. Professor, Department of Oral Medicine \& Radiology, C.S.M.S.S. Dental College \& Hospital, Kanchanwadi, Paithan Road, Aurangabad, Maharashtra; ${ }^{M}$ M.D.S. Reader, Department of Oral Medicine \& Radiology, C.S.M.S.S. Dental College \& Hospital, Kanchanwadi, Paithan Road, Aurangabad, Maharashtra; 5P.G.Student, Department of Periodontia, M.G.V. Dental College \& Hospital, Nashik, Maharashtra.
\end{abstract}

\section{ABSTRACT}

Objectives: The aim of this study was to test the interns for their understanding of the importance of radiology and its judicious use.

Methods: The study was carried out with 16 pretested questions which were closed ended. The study was conducted among the trainee dentists who were pursuing internship. The duration of the study was 2 weeks. A total of 115 trainee dentists participated, 90 females and 25 males. The data obtained was fed into Microsoft Excel (Redmond WA). The statistical analysis was performed with SPSS Version 17 to check for statistical significance.

Results: The results of the study are comprehensively presented in observation table and also in graph.

Conclusions: Based on our study, it can be concluded that, the intern dentists have a satisfactory knowledge of radiation protection methods. However, in order to improve further, continuing education programmes, at regular intervals are necessary to keep them updated about radiation protection protocols.

Key Words: Radiology, Safety, Exposure

\section{INTRODUCTION}

Dental Imaging is an integral part of clinical dentistry. As a result, radiographs are often referred to as the clinician's main diagnostic aid. However it carries a potential harm and the exposure to dental radiation should be minimized where practicable. ${ }^{[1]} \mathrm{X}$-rays are a form of high-energy electromagnetic radiation. They can penetrate the human tissues. When $\mathrm{X}$-rays strike matter such as a patient's tissues, the photons can completely be scattered with no loss of energy or can be absorbed with total loss of energy or scattered with some absorption and loss of energy or can be transmitted unchanged.
The International Commission on Radiological Protection (ICRP) recommended that all patient exposure must be justified and kept as low as possible. So it is a mandatory to follow ALARA principle "As Low As Reasonably Achievable" during dentist routine work. ${ }^{[2,3]}$ This principle was adopted to minimize radiation dose. In general, ALARA principle takes into consideration the justification for the radiological study and taking the imaging examination with the least amount of radiation that can produce radiographs of reasonable diagnostic quality. As a result radiographs should only be taken at the minimum dosage with reasonable information yield in as much as a safer method is not available. ${ }^{[4]}$ Consequently

Corresponding Author:

Dr. Ashish Bhaskar Zope, P.G. Student, 35, Zambad estate, New Shreyanagar, Aurangabad-431005, Maharashtra, India. Mob. No.9730548545; Email: drabyz@rediffmail.com

ISSN: 2231-2196 (Print)

Received: 09.06.2019
ISSN: 0975-5241 (Online)

Revised: 20.06 .2019
Accepted: 04.07.2019 
operators of radiographic equipment should be thoroughly familiar with radiation safety practices and radiation regulations to protect themselves, their colleagues and the patients.

The effects of x-rays are harmful to living tissues and it is sufficiently intense and detrimental to cause cancer, leukemia and genetic damage. ${ }^{[5,6]}$ These biological effects can be divided into Deterministic and stochastic effects. ${ }^{[3]}$ Deterministic effects are those effects in which the severity of the response is proportional to the dose. These effects occur in all people when the dose is large enough ${ }^{[7]}$ Stochastic effects are those for which the probability of occurrence of the change, rather than its severity, is dose dependent. ${ }^{[3]}$ The stochastic effects thus lay the patient's and the operating personals in a high risk zone as it does not have dose thresholds..$^{[3]}$ Thus, dental radiographs should be only prescribed for patients when the benefit of disease detection outweighs the risk of damage from X-rays. ${ }^{[8]}$ Thus reducing the radiation dose should be an important consideration for dental professionals. ${ }^{[9]}$ In order to reduce patient's exposure to radiation, appropriate use of a lead apron, thyroid collar, right collimation and suitable technique are included in the practice of radiologic examination. Every radiographic exposure to the patient should be clinically justified and each exposure should be expected to give the benefit of a confirmed diagnosis. ${ }^{[10]}$

This study focuses on the awareness level about radiation protection among trainee dentists. The aim of this study was to test the trainee dentists about their understanding of the importance of radiology and its judicious use. The study was carried out with 16 pretested questions which were closed ended. ${ }^{[12]}$

\section{MATERIALS AND METHODS}

A self formulated printed questionnaire consisting of 16 multiple choice questions was circulated among the trainee dentists and their responses were received. Only those dental students who were pursuing internship were included in this study. The duration of the study was 2 weeks. A total of 115 trainee dentists participated in the study of which 90 were females and 25 males.

\section{STATISTICAL METHODS}

The data obtained was fed into Microsoft Excel (Redmond WA). The statistical analysis was performed with SPSS Version 17 to check for statistical significance.

\section{RESULTS}

The study was conducted among the trainee dentists who were pursuing internship. The duration of the study was 2 weeks. A total of 115 trainee dentists participated of which 90 were females and 25 males. The results are comprehensively presented in observation table and also in graph.

\section{DISCUSSION}

Our study shows that $33.9 \%$ of the respondents, get exposed to radiation several times in a month, during clinical posting. $35.7 \%$ percent respondents feel that the importance of imaging in dentistry is high. When questioned about various methods to protect the patient from radiation exposure, majority $(62.6 \%)$ responded as lead aprons, shields and time of exposure, which correlates with the study done in Chennai. ${ }^{[12]}$ Our study reveals thyroid is the organ to be protected during radiologic exposure as responded by $53.9 \%$ of the participants, which correlates with the study done in Chennai. ${ }^{[12]}$ $36.5 \%$ responded that, $6.0 \mathrm{REM} / \mathrm{year}$, is maximum permissible dose for occupationally exposed persons, while, $33 \%$ responded 2.0rems/year as the maximum permissible dose for non-occupationally exposed persons. $40.9 \%$ respondents opined that the greatest risk of radiation induced thyroid cancers is above 30 years of age.

$33 \%$ participants responded that, rectangular PID is best and another 33\% participants responded that, round PID is best. $39.1 \%$ participants responded that $\mathrm{E}$ films cause $60 \%$ reduction in radiation as compared to D films. $40 \%$ participants responded that, 6 months is the minimum duration of exposure, for the usage of personnel monitoring device. For the question regarding the holding of film during exposure, $54.8 \%$ responded in the negative, which reduces unnecessary radiation exposure, which correlates with the study done in Vikarabad, Telangana, India. ${ }^{[11]}$ When asked about the holding of radiographic tube during exposure, majority $(62.6 \%)$ of the respondents of our study replied in the negative. $39.1 \%$ participants replied that radiographs can be taken for pregnant patients only after weighing risk benefit ratio. According to $46.1 \%$ participants, radiographs can be taken for a pregnant patients in $2^{\text {nd }}$ trimester. It can be seen from the above histogram that, majority of the respondents $(67.8 \%)$ of the study follow the position and distance rule and hence reduce their risk of radiation exposure significantly. $44.3 \%$ replied that $\mathrm{X}$ ray room can be made safe by lead walls and walls constructed of gypsum wallboard.

Analysis of subjective questions of our study (Question numbers 1,2,3,11, 12 and 15) indicates fairly good understanding of radiation protection protocols. However, analyzing the response to objective questions (Question numbers 4, $5,6,7,8,9,10,13,14$ and 16 of our study), only 293 correct responses were received against 1150 maximum possible, which indicates that level of awareness of radiation protection is fairly low among intern dentists. To help them in minimizing the exposure to the dental fraternity or patients with 
focus on welfare of the patients we emphasize continual education programs at regular intervals at institutional level and national level for strict observance of various radiographic protection guidelines. ${ }^{[11]}$

\section{CONCLUSION}

Based on our study, it can be concluded that, the intern dentists have a satisfactory knowledge of radiation protection methods. However, in order to improve further, continuing education programmes, at regular intervals are necessary to keep them updated about radiation protection protocols.

\section{ACKNOWLEDGEMENT}

Authors are thankful for the skillful and generous support of Dr.AmrutaMadhukarBansode (M.D.S., O.M.R.) and Dr. Kapil Dhananjayrao Pawar (M.D.S., O.M.R.), (Sr. Lecturers, Department of Oral Medicine \& Radiology; C.S.M.S.S. Dental College \& Hospital; Kanchanwadi; Paithan Road; Aurangabad; Maharashtra).

Authors acknowledge the immense help received from the scholars whose articles are cited and included in references of this manuscript. The authors are also grateful to authors / editors / publishers of all those articles, journals and books from where the literature for this article has been reviewed and discussed.

\section{Sources of financial / equipment support: None.}

Conflicts of interest : Nil.

\section{Abbreviations:}

REM: Roentgen Equivalent Man. It is a measurement that correlates the dose of any radiation to the biological effect of that radiation.
PID: Position Indicating Device. It is a device to guide the direction of $\mathrm{X}$ ray beam during the exposure of dental radiographs.

\section{REFERENCES}

1. National Council for Radiation protection and Measurements (NCRP). Radiation protection in dentistry. Bethesda Md: National council for radiation protection and measurements; 2003.

2. ICRP. Recommendations of the ICRP. ICRP Publication 26. Ann ICRP, 1977; 1: 1-53.

3. White SC, Pharoah MJ. Chapter 2: Radiation biology in Oral Radiology Principles and Interpretation, Fifth edition. Mosby, St. Louis 2004, p. 25 - 46.

4. Freeman JP, Brand JW. Radiation doses of commonly used dental radiographic surveys. Oral Surg Oral Med Oral Pathol., 1994; 77: 285-9.

5. Royal College of Radiologists and National Radiological Protection Board. Patient dose reduction in diagnostic radiology. Document of the National Radiological Protection Board, 1990; $1(2)$.

6. Barr JH, Stephens RG. Radiological health, In Dental radiology, Pertinent basic Concepts and their Applications in Clinical Practice. Philadelphia, WB Saunders, 1980; p. 66-80.

7. Frommer HH. Biological effects of Radiation, In Radiology for Dental Auxillaries, 6th edition St. Louis, Mosby - year book, 1996; p. $49-67$.

8. Haring JI, Lind LJ. Chapter 5: Radiation protection in Textbook of Dental Radiography Principles and Techniques. W.B. Saunders Company, 1996, p. $64-79$.

9. Shahab S, Kavosi A, Nazarinia H, Mehralizadeh S, et al. Compliance of Iranian dentists with safety standards of oral radiology. Dentomaxillofac Radiol., 2012; 41:159-64.

10. Prabhat MP, Sudhakar S, Praveen B, Ramaraju K. Knowledge, attitude and perception(KAP) of dental undergraduates and interns on radiographic protection - A questionnaire based crosssectional study. J Adv Oral Res., 2011; 2: 45-50.

11. Swapna et al.; BJMMR, 19(7): 1-7, 2017; Article no.BJMMR.30761

12. Tamizh Paavai .THA, Jayanth Kumar V. To Study Awareness About Radiation Protection Among Dental Students Of Chennai-A Questionnaire Based Study. Int J Pharm Bio Sci 2017 Jan ; 8(1): B 542-551

\section{Table 1: Observations}

\begin{tabular}{|c|c|c|c|c|}
\hline & $\begin{array}{c}\text { A } \\
\text { Responses(\%) }\end{array}$ & $\begin{array}{c}\text { B } \\
\text { Responses(\%) }\end{array}$ & $\begin{array}{c}\text { C } \\
\text { Responses(\%) }\end{array}$ & $\begin{array}{c}\text { D } \\
\text { Responses(\%) }\end{array}$ \\
\hline 1 & $31(27)$ & $34(29.6)$ & 39 (33.9) & $11(9.6)$ \\
\hline 2 & $4(3.5)$ & $20(17.4)$ & $41(35 \cdot 7)$ & $50(43.5)$ \\
\hline 3 & $19(16.5)$ & $13(11.3)$ & $11(9.6)$ & $72(62.6)$ \\
\hline 4 & $20(17.4)$ & $62(53.9)$ & $22(19.1)$ & $11(9.6)$ \\
\hline 5 & $24(20.9)$ & $42(36.5)$ & $29(25.2)$ & $20(17.4)$ \\
\hline 6 & $27(23.5)$ & $34(29.6)$ & $38(33)$ & $16(13.9)$ \\
\hline 7 & $18(15 \cdot 7)$ & $47(40.9)$ & $27(23.5)$ & $23(20)$ \\
\hline 8 & $38(33)$ & $38(33)$ & $23(20)$ & $16(13.9)$ \\
\hline
\end{tabular}


Table 1: (Continued)

\begin{tabular}{ccccc} 
& A & B & C & D \\
& Responses(\%) & Responses(\%) & Responses(\%) & Responses(\%) \\
9 & $19(16.5)$ & $36(31.3)$ & $45(39.1)$ & $15(13)$ \\
10 & $26(22.6)$ & $46(40)$ & $42(36.5)$ & $1(0.9)$ \\
11 & $4(3.5)$ & $63(54.8)$ & $36(31.3)$ & $12(10.4)$ \\
12 & $5(4.3)$ & $72(62.6)$ & $17(14.8)$ & $21(18.3)$ \\
13 & $33(28.7)$ & $30(26.1)$ & $45(39.1)$ & $7(6.1)$ \\
14 & $12(12.2)$ & $53(46.1)$ & $34(29.6)$ & $14(12.2)$ \\
15 & $78(67.8)$ & $16(13.9)$ & $16(13.9)$ & $5(4.3)$ \\
16 & $41(35.7)$ & $16(13.9)$ & $51(44.3)$ & $7(6.1)$ \\
\hline
\end{tabular}

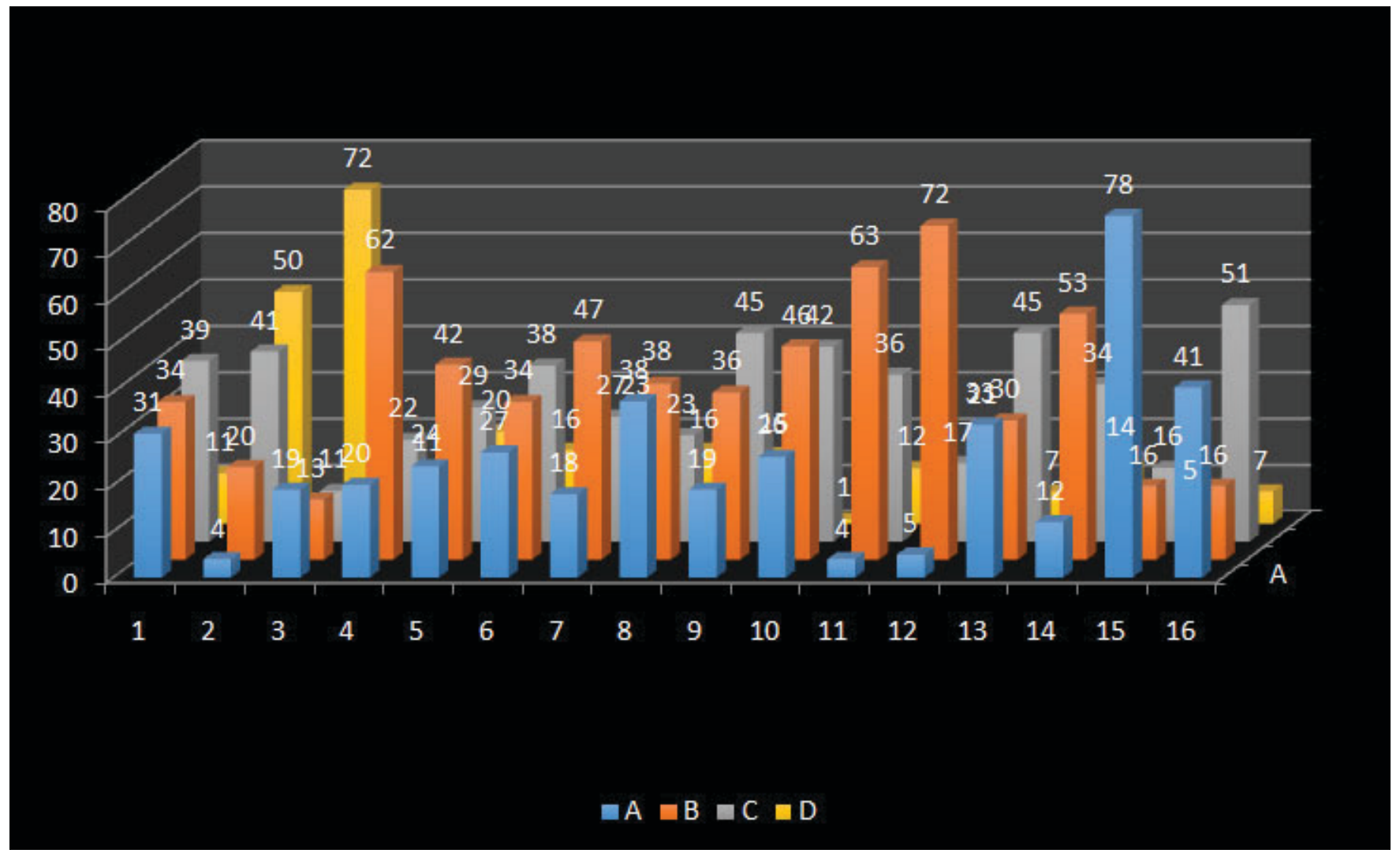

Graph 1: 


\section{ANNEXURE:}

\section{Questionnaire:}

1. How many times do you get exposed to radiation?
A. several times in a day
B. several times in a week
C. several times in a month
D. none of the above

2. In your opinion how important is imaging in dentistry?
A Low
B. Moderate
C. High
D. Very high

3. Mark the various options to reduce radiation exposure to patient that you are aware of?
A. lead aprons
B. shields
C. time of exposure
D. all of the above

4. What is the most important organ that has to be protected during dental radiography?
A. gonads
B. thyroid
C. skin
D. bone marrow

5. What is the maximum permissible dose for occupationally exposed persons?
A. $5.0 \mathrm{rems} / \mathrm{year}$
B. $6.0 \mathrm{rems} / \mathrm{year}$
C. 4.0rems/year
D. $3.0 \mathrm{rems} /$ year

6. What is the maximum permissible dose for non-occupationally exposed persons?
A. $0.1 \mathrm{rem} /$ year
B. $1.0 \mathrm{rem} /$ year
C. $2.0 \mathrm{rems} /$ year
D. $0.2 \mathrm{rem} /$ year

7. Greater risk of radiation induced thyroid cancers is seen in the age group of-
A. Below 30 years
B. Above 30 years

C. Below 20 years

D. Between 20 years and 30 years

8. Which is the best PID?
A. Rectangular
B. Round
C. Either of the above
D. Cannot say

9. $\quad$ //O films of speed $E$ reduce how much radiation as compared to D films?
A. $50 \%$
B. $40 \%$
C. $60 \%$
D. $30 \%$

10. What is the minimum duration of exposure for using personnel monitoring devices?
A. 3 months
B. 6 months
C. 1 year
D. 2 years

11. Do you hold the radiographic film during exposure?
A. Yes
B. No
C. Sometimes
D. Never

12. Do you hold the radiographic tube during exposure?
A. yes
B. no
C. Sometimes
D. Never

13. Can periapical radiographs be taken for a pregnant woman?
A. Yes
B. No
C. Only after weighing risk benefit ratio
D. Cannot say

14. Preferably in which trimester?
A. First
B. Second.
C. Third.
D. Cannot say. 
15. Do you follow the position and distance rule?
A. Yes
B. No
C. Sometimes
D. Never

16. What are the measures that have to be taken to make the X-ray room safe from exposure?
A. Lead walls
B. walls constructed of gypsum wallboard

C. both

D. none of the above

Answer Key:

4-D; 5-A; 6-A; 7-A; 8-A; 9-A; 10-A; 13-C; 14-C; 16-C. 